\title{
Migraciones, diversidad cultural y teoría de la cultura
}

\author{
Rosa Aparicio \\ Andrés Tornos \\ Universidad Pontificia Comillas \\ Instituto Universitario de Estudios sobre Migraciones \\ raparicio@iem.upcomillas.es \\ tornos@iem.upcomillas.es
}

Recibido: 17-04-2007

Aceptado: 25-06-2008

\section{Resumen}

En España la temática del multiculturalismo empezó a relacionarse con las migraciones a propósito de las dificultades experimentadas en los colegios por los hijos de los inmigrantes, cuando éstos se encontraban con unos planes de estudio, unos criterios educativos y un trato diario que privilegiaban frente a ellos a los nativos.

Frente a esta discriminación quiso promoverse la multiculturalidad. Más al no precisarse bien el significado que se quería dar a la palabra cultura, muy ambiguo entre nosotros en su uso corriente, vino a esencializarse y a "racializarse» la diferencia cultural, como si significara algo común, intangible e indeleblemente impreso en los provenientes de cada país.

Pero así no llegaban a articularse bien las cuestiones específicas que se plantean por razón de las diferencias interculturales. El artículo quiere avanzar hacia esa articulación, apoyándose en la noción más precisa de cultura que ha estado usándose en la tradición antropológica.

Palabras clave: multiculturalismo, antropología, discriminación.

\section{Abstract. Migrations, cultural diversity and theory of the culture}

In Spain, the topic of multiculturalism was first linked to migration in connection with the difficulties experienced in school by immigrant's children, when these were confronted with study plans, educational criteria and everyday dealings which privileged native children.

Multiculturalism was thus promoted as one way of facing this discrimination. But, as the term culture (a term already very ambiguous in its everyday use amongst us) was adopted without precising its meaning, cultural differences came to be essentialized and "racialized", as if they signified something common, intangible and indelibly imprinted in those coming from the same country of origin.

This could not lead to a good articulation of the specific questions which arise when dealing with cultural differences. The article wishes to progress in this articulation by supporting it on the more precise notion of culture which has traditionally been used by anthropologists.

Key words: multiculturalism, anthropology, discrimination. 


\section{Sumario}

1. Significados de la palabra cultura en el uso común

2. El significado clásico de la palabra cultura en antropología

3. Crisis y transformación del concepto clásico de cultura
4. Frustración o conflictos culturales y derechos culturales

Bibliografía

En España, la temática de la cultura empezó a relacionarse con las migraciones a propósito de los modelos de la enseñanza escolar, de los que se decía que debían respetar el multiculturalismo. Fue, sin embargo, luego, debido a la gran resonancia pública obtenida por la recepción que prestaron los medios de comunicación a la obra de G. Sartori La sociedad multiétnica. Pluralismo, multiculturalismo y extranjeros ${ }^{1}$, cuando la cuestión adquirió la difusión que ha venido a tener. Pero, desgraciadamente, todo esto, en nuestra opinión, habría ayudado bien poco a que se clarificaran las cuestiones que más afectan a los inmigrantes por razón de su diversidad cultural.

En esta falta de clarificación, habría influido sobre todo el hecho de que la palabra cultura, al saltar de esa manera a la atención, ha perdido el significado preciso que, en los campos de la antropología y la psicología social, le permitían funcionar como una buena herramienta de análisis, útil para explicar las relaciones sociales e intervenir en ellas. Y eso apenas pudo dejar de ocurrir, primero, porque el uso de la palabra cultura, en el castellano corriente, venía siendo muy ambiguo. Segundo, porque, con ocasión de su ambigüedad, el significado de la palabra había ido «racializándose» y «esencializándose», es decir, convirtiéndose en un eufemismo sustitutivo de las palabras raza o etnia, entendidas como portadoras de una esencialidad diferencial estable en el conocer, valorar y comportarse ${ }^{2}$.

En seguida se explanará esto más despacio, pero ya es fácil de ver que si los problemas culturales concomitantes con las migraciones fueran los de poner a los nativos ante inmigrantes programados innatamente para atenerse a costumbres distintas, entonces lo único que se podría decidir sobre tales problemas es que cada uno habría de ser libre para seguir sus costumbres — mientras no perjudicaran a los demás-, y que nadie debería ser discriminado por eso. Y si sólo se llega hasta ahí, se queda sin utilizar todo lo que la antropología y la psicología social han sacado a luz sobre las raíces de la pertenencia cultural de las personas, sobre su evolución o su cambio cultural, sobre las relaciones interculturales, sobre la identidad cultural, sobre los sistemas de

1. Madrid, Taurus, 2001.

2. Crítica breve, pero muy terminante, de la comprensión esencialista de la cultura en E. LAMO DE EsPINOSA (ed.) (1995), «Fronteras culturales», en Culturas, estados, ciudadanos, Madrid, Fundación Ortega y Gasset, p. 13-79. Referencia en la bibliografía. 
conocimiento en que se basa la diversidad de costumbres... Igualmente, también se ignora lo que el derecho internacional público ha elaborado sobre los derechos culturales.

Por eso, aquí nos ocuparemos primeramente, en sendos apartados, de los significados que, respectivamente, se han dado al término cultura en el uso común y en la antropología clásica, sobre todo para subrayar que ésta última, a lo largo de casi cien años, muchas veces luchando contra usos lingüísticos comunes, ha estado intentando hacer operativo el uso del concepto de cultura. Es decir:

- Útil para dar razón de los modos de convivencia de una determinada sociedad o pueblo.

- Útil, por eso mismo, para entender la alteración de dichos modos de convivencia.

- Útil en su uso práctico para plantear y resolver los problemas relacionados con dicha alteración (que no se identificarían bien si se los mira simplemente como problemas de diferencias innatamente hereditarias en las costumbres).

A continuación, un tercer apartado tratará brevemente de la crisis y de la transformación de ese concepto clásico de la cultura, y un cuarto apartado, de las dificultades o de los conflictos estrictamente culturales, así como también de los desarrollos habidos en el campo de los derechos culturales.

\section{Significados de la palabra cultura en el uso común}

María Moliner, en su Diccionario del Uso del Castellano ${ }^{3}$, enumera los siguientes signficados de la palabra cultura:

- Conocimientos no especializados adquiridos individualmente por una persona mediante el estudio, las lecturas, los viajes, etc.

- Conjunto de los conocimientos, el grado de desarrollo científico e industrial, el estado social, las ideas, el arte, etc., de un país o de una época (cultura clásica o cultura moderna).

- Conjunto de la actividad espiritual de la humanidad (historia de la cultura $)^{4}$.

Ya aquí aparece la ambigüedad que antes se mencionaba, puesto que la cultura se entiende unas veces como cuestión individual, otras veces como cuestión colectiva de un país y otras veces como atributo (¿esencial?) de la especie humana en su conjunto. Pero, además, unas veces la cultura es adquisión individual mediante estudio, lecturas, etc., otras veces es adquisición colectiva y no

3. Madrid, Editorial Gredos, 1979, reimpresión.

4. Las cursivas son nuestras (A. T. y R. A.). 
pretendida de todo un país o una época. Y unas veces es desarrollo tecnológico y otras veces es actividad espiritual.

Por lo demás, la misma María Moliner enumera los cinco adjetivos siguientes como los más utilizados para cualificar a la cultura, todos ellos fuertemente valorativos: deficiente, sólida, vasta, adelantada, atrasada.

Ya se ve que, discurriendo con arreglo a estos usos lingüísticos, lo que habría de hacerse con las diferencias culturales es complementar sus deficiencias, dar solidez a su debilidad, anchura a su estrechez, actualización a sus atrasos. Y entonces el admitir la multiculturalidad, o incluso la interculturalidad, sería inaceptable. O todo lo más sería una especie de misericordia provisional para con los afectados por niveles culturales deficientes, una misericordia que esperaría pacientemente a que ellos fueran superando sin violencia su atraso, su estrechez de horizontes y su debilidad de pensamiento. Y nos tememos que ésta es la manera popular de entenderse lo que llamos multiculturalidad.

Lo que, desde esta perspectiva, no se entiende es:

- ¿Por qué habría de resultarles violento y penoso, a los que lo padecen, remediar su atraso, su estrechez y su debilidad cultural?

- ¿Qué efectos sociales tendría sobre ellos el resistirse a transformar sus estilos culturales?

- ¿Se necesitaría alguna pedagogía especial, distinta de las pedagogías usuales en los currículos escolares, para promover los cambios culturales o las relaciones interculturales?

- ¿Por qué?

- ¿Qué principios podrían guiar a esta pedagogía?

Esto a propósito de los significados atribuidos, según María Moliner, a la palabra cultura en el uso corriente. Pero hay que reconocer que esos significados son generalmente algo más ricos cuando se habla de las migraciones. Porque entonces el uso común se complementa con dos matices muy importantes. Primero: entendiendo que la cultura no sólo es cuestión de conocimientos, sino también y más aún de costumbres; segundo: entendiendo que lo cultural no se refiere primariamente a costumbres individuales, sino prioritariamente a costumbres compartidas por un colectivo y vividas como tales.

Éste es un gran paso para entender las cuestiones sobre la interculturalidad. Pero falta aclarar, ¿es que de veras se comparten del todo ciertas costumbres en todos o en algunos colectivos?, ¿por qué?, ¿por qué los miembros de ese colectivo creen que sus costumbres son compartidas por todos ellos?, ¿por qué experimentan resistencias frente al cambio de esas costumbres compartidas?, ¿cómo se producen los cambios culturales?

El poder responder a estas preguntas sería de gran ayuda para plantear bien las cuestiones culturales relacionadas con la inmigración y a ello contribuiría el esforzarse por dar a la palabra cultura el significado más preciso que ha ido adquiriendo en el campo de la antropología. Pasamos a él. 


\section{El significado clásico de la palabra cultura en antropología}

Se fue formando a través de muchas discusiones, pero, a través de ellas, llegaron a prevalecer unos cuantos aspectos muy generalmente admitidos, que son los que necesitamos para tratar nuestro tema.

Puede considerarse representativa de la situación inicial la antigua definición descriptiva de la cultura propuesta por Tylor en Primitive Culture (1871):

[...] la cultura es todo un complejo que incluye los conocimientos, las creencias, el arte, la moral, las leyes, las costumbres y todas las demás disposiciones y hábitos adquiridos por el hombre, en tanto que miembro de una sociedad.

Implícito queda algo muy importante, y es que Tylor propuso su definición para precisar, a la luz de la experiencia práctica de los antropólogos, aquello que hace vivir a los distintos pueblos tal como viven. Y los antropólogos que criticaron o quisieron afinar esta definición lo hicieron porque pensaban que en ella faltaba algo o sobraba algo precisamente para eso: para definir concretamente lo que determina la forma de convivir de cada pueblo, por extraña que parezca.

Muy generalmente, en la definición se echaba en falta que ésta, enumerando una porción de cosas, no indicaba lo que las unifica. Y así, en lugar de mostrar un «algo» único que pudiera dar razón de las formas de vida de los pueblos, parecía sugerir que esas formas de vida dependen de muchas cosas sueltas y distintas (conocimientos, moral, disposiciones...).

Pero cuando quiso concretarse qué es lo que unifica o enlaza a los distintos elementos nombrados por Tylor, surgieron muchas discusiones, aunque no se abandonara la idea de que la cultura es un complejo unitario de todo lo nombrado por él. Unos mantendrían que todos los elementos de la cultura se unifican como un complejo proceso de adaptación al medio; otros mantendrían que la cultura es, ante todo, un conjunto de códigos compartidos para interpretar los signos de sí que dan los fenómenos, etc. ${ }^{5}$.

No pertenece a este contexto el entrar en esas discusiones especializadas. Simplemente, basta retener que la cultura abarca todos aquellos elementos nombrados por Tylor, pero uniéndolos como en un todo único más o menos estrechamente ensamblado, incluso estructurado, en el sentido estricto de esta palabra, según aspectos más o menos esenciales, más centrales o más periféricos.

Dejando, pues, de lado aquellas discusiones, deben retenerse, al tratar de la problemática del multiculturalismo, dos rasgos de la definición de Tylor que

5. Carlos Giménez ha resumido los debates habidos en torno al concepto de cultura en el artículo referente a ésta que publicó en S. Giner, E. LAMO DE EsPINOSA y C. TORRES (eds.) (1998), Diccionario de Sociología, Madrid, Alianza. Una revisión más razonada de la evolución habida se expone en el texto de R. M. KEESING (1993), "Teorías de la cultura», recogido por Honorio VELASCO en Lecturas de antropología social y cultural, Madrid, UNED, p. 43-74. 
se han validado durante más de cien años en el estudio de las culturas y que afectan a lo que puede esperarse y lograrse en los intentos multiculturalistas: el de la complejidad de los elementos que las culturas abarcan y el del modo de su adquisición.

La complejidad primero. Es de notar que, según Tylor, una cultura no sólo incluye repertorios de conocimiento, sino también creencias y usos morales, además de otras disposiciones y hábitos — entre los cuales siempre se han incluido actitudes emocionales o afectivas. Ya se ve que esto aleja a la comprensión antropológica de la cultura de los modos casi exclusivamente cognitivistas de entenderla descritos por María Moliner en su Diccionario de Uso del Castellano, pero también la aleja de muchos planteamientos actuales del debate sobre multiculturalismo, en la medida en que éstos se plantean desatendiendo a los componentes extraescolares, emocionales y de «habituación cuasi mecánica», que subyacen a las pertenencias culturales y demandan ser atendidos al promover cambios culturales y modelos de interculturalidad.

Esto nos lleva al segundo de los elementos que la antropología de la cultura demandaría si se tuvieran en cuenta al hablar de multiculturalismo: el relativo a la peculiaridad de la adquisición de una cultura determinada. La definición de Tylor reservaba el nombre de cultura para aquello que uno adquiere en tanto que miembro de una sociedad. Es decir: no en tanto que uno pudo ser alumno de un centro de enseñanza determinado, ni en tanto que viajó por diversos países, ni en tanto que se dedicó a ciertos trabajos, etc. Más bien en tanto que uno está en un cierto lugar o sector de la humanidad y adquiere insensiblemente, en la interacción con aquellas personas que le son cercanas, los repertorios de conocimientos que por ellas comúnmente se utilizan, así como también una amplia experiencia de cómo entre ellas se valoran comúnmente las cosas. En este sentido, sigue manteniéndose por la antropología el uso de no concebir a la cultura como una cuestión individual, ni a los cambios culturales como cambios individuales ${ }^{6}$.

Pero, normalmente, no sabe uno qué conocimientos ni qué disposiciones ha adquirido como por ósmosis en el lugar de la sociedad en que se formó y que usa como por contagio, sin ninguna selección consciente frente a conocimientos y disposiciones personalmente controlados. Por eso puede decirse que la cultura que uno tiene es inconsciente para él, al menos en cierto sentido, y que por eso debe estudiarse:

6. Lo que sí ha cambiado entre muchos antropólogos es la concepción de los grupos a los que la antropología clásica consideraba portadores de una cultura. Y es que la mundialización ha llevado a que prácticamente no existan los colectivos aislados sobre sí mismos y de culturas bastante monolíticas que, durante largo tiempo, ocuparon a la antropología. Pero culturas diferentes y compartidas hay hoy en día, a pesar de la mundialización, aunque sean compartidas más desigualmente. Geertz lo ha subrayado muy convincentemente en su ensayo «El mundo en pedazos: Cultura y política en el fin de siglo», publicado en Reflexiones antropológicas sobre problemas filosóficos, Barcelona, Paidós, 2002, p. 211-227. En este sentido, se ha dicho que la tarea actual de la antropología cultural es estudiar la distribución social de los significados. 
- Desde fuera de quien la comparte.

- Y principalmente en sus efectos.

¿Y cuáles son esos efectos?

Para los relacionados con las migraciones, nos importan sobre todo tres, que podemos considerar como funciones de la cultura: una función cognitiva o epistemológica, una identitaria y una, más difícil de nombrar, que podemos llamar de creación de un medio histórico.

$\mathrm{Al}$ atribuir a la cultura una función cognitiva, está recordándose que la cultura asimilada por un individuo al socializarse en su medio nativo canaliza posteriormente, mientras no se desidentifique de ella, sus posibilidades y su modo de adquirir conocimientos, así como el manejo que hará de esos sus conocimientos, sobre todo en la vida diaria. Ello quiere decir que sus hábitos interpretativos estarán sobreadaptados a sus contextos de origen e infraadaptados a los de ámbitos sociales distintos. De donde se seguirá que él, cuando se encuentre fuera del ámbito de formación de su cultura de origen, se encontrará muchas veces desorientado sobre el significado que, alrededor de él, se da a las cosas y sobre el sentido que se atribuye a lo que él mismo hace. Por ejemplo: un europeo que, en Arabia Saudí, se monta en un ascensor con una cabina grande y acompañado solamente por otro viajero, si éste se le arrima en la cabina hasta casi empujarle, se desorientará y no sabrá cómo interpretar la acción. Pero eso en Arabia sería una muestra común de cortesía ${ }^{7}$.

$\mathrm{Al}$ decir que la cultura tiene una función identitaria no sólo quiere indicarse que uno muy generalmente se identifica como miembro del entorno sociocultural del que procede ${ }^{8}$, sino también que a cada uno, en el ámbito de su cultura, le es atribuida una determinada identidad conforme al sistema de identidades vigente en aquel ámbito ${ }^{9}$. En ese ámbito, lo que de él se espera y el modo de valorarle se corresponderá con lo atribuido al rol identitario correspondiente (v. g. el de ser uno un jefe, un hechicero, un diputado, un médico, un inmigrante). Por eso, comúnmente, uno, al estar fuera del ámbito de la propia cultura, tiende a perder su sitio en el sistema de las identidades y a necesitar un esfuerzo extra para que se le trate con arreglo a la identidad que él personalmente se atribuye.

Cuando se dice que las culturas tienen también la función de «crear un medio histórico» quiere decirse que las culturas recrean constantemente en sus ámbitos la manera común de entenderse los contextos en que el sujeto puede

7. Todo el contenido de la influyente obra de C. GEERTz (Interpretation of cultures, Nueva York, Basic Books, 1973) desarrolló este tema de diversas maneras. Tiene traducción castellana en Gedisa.

8. Sobre la permanencia e incluso intensificación de este fenómeno en el mundo actual, ver J. Friedman (1994), Cultural identity, Londres, Sage, p. 78-90.

9. Sobre la atribución de identidades en ámbitos culturales distintos, ver M. COHEN-EMERIQUE (1989), "Connaissance d'autrui et processus d'attribution en situations interculturelles", en J. RETSCHISKY y otros (1989), La recherche interculturelle, tomo I, París, L'Harmattan, p. 26-46. 
actuar como agente social y «racional», es decir, en tanto que agente conocedor de cómo se entienden alrededor de él esos contextos y qué opciones, así entendidas las cosas, le permitirán actuar con vistas a participar responsablemente, no a ciegas, en la marcha social de sus asuntos. Por eso mismo, el indivíduo, al estar en el ámbito de una cultura extraña, no puede contar con que sabrá leer los contextos en que actúa para prever así los resultados de su interacción con otros y elegir bien los medios que le llevarán a conseguir racionalmente sus fines ${ }^{10}$.

Y como consecuencia de todo ello, los inmigrantes que llegan desde culturas realmente ajenas a la del país de destino, no pueden menos que verse afectados por el colapso de lo que les aportaban sus culturas para orientarse en la convivencia (función cognitiva de sus culturas), para situarse adecuadamente en el sistema de identidades al que están accediendo (función identitaria de sus culturas) y para actuar razonable y responsablemente con arreglo a la lógica que, según el sentir común y difuso, configura las situaciones de la vida diaria (función cultural de creación de medios históricos).

Estas precisiones indicarían cómo responder a las preguntas que más arriba se plantearon acerca de por qué había de resultarles penoso, a los socializados en culturas menos desarrolladas, el abandonarlas para ajustarse a los usos de países más desarrollados, o acerca de los efectos sociales que, sobre ellos, tendría el resistirse a transformar sus estilos culturales, o acerca del modo de ayudarles en los problemas de ello derivados, etc.

En cuanto a lo primero, no puede sino resultar obvio que le resultará a uno penoso desprenderse de las formas de entender la vida por las que siempre se ha guiado, mientras no llega a tener una experiencia personal de lo que dan de sí otras formas de entender la vida. Gracias a las primeras ha estado dando sentido a su actuar, ha superado dificultades, ha gozado, ha construido proyectos. Quedarse sin ellas es como volverse uno un átomo loco en un mundo que gira por órbitas desconocidas. Los sentimientos y los proyectos se le dislocan a uno. El suelo afectivo se le mueve — si es que no le desaparece a uno bajo los pies.

Pero el problema está en que el hacerse uno fuerte en sus primigenias adscripciones culturales, una vez consumada la emigración, puede cerrarle frente a los hábitos culturales del país de su arribada. Entonces le impide «socializarse» del todo en los nuevos contextos de vida en los que estará ingresando. No los descifrará bien. Actuará trabándose en constantes malentendidos. Se inclinará a recluirse en las redes de relación reservadas a sus connacionales, porque será sólo en ellas donde se encuentre a sí mismo.

Aunque también puede ocurrir que el mantenimiento de la adscripción cultural a su origen no le impida a un inmigrante el ir captando los usos y las costumbres del país a que llegó, gracias al hecho de establecer interacción con

10. Acerca de la configuración cultural de las situaciones y de la importancia de captarla, ver E. T. HALL, "Beyond culture», en Situation, culture building block, cap. 9, p. 129-149. 
él. Desarrollará, entonces, un posicionamiento cultural mestizo, capaz de transitar sin inadaptación por los distintos medios culturales ${ }^{11}$. Y tal vez éste sería el itinerario ideal para un sujeto que debe hacer frente a los esfuerzos no pequeños de la emigración. Porque para ello le vendrá bien no haber renegado de su socialización anterior, que le aportará criterios y energías para enfrentarse con sus oscuridades y dificultades iniciales.

La opción por este itinerario ya se ve que no es cuestión de explicaciones teóricas - porque la participación en una cultura no sólo implica conocimientos y decisiones voluntaristas, sino también y, más aún, actitudes emocionales, sentimientos, hábitos mecánicos. Por otra parte, la sociedad receptora habría de implicarse a un doble nivel en el buen resultado de esta solución mestiza: en el nivel de las actitudes y en el de las innovaciones estructurales.

En el de las actitudes, porque habría de aceptar de buen grado que, en medio de ella, surgieran posiciones culturalmente diferentes. En el de las innovaciones estructurales, porque, en la estructura social informal, necesitarían abrirse espacios aceptados para nuevos estilos de ciudadanía. Lo que esto supone seguramente no es muy diferente de lo que hubo de conseguir la llamada "clase obrera" para llegar a tener un sitio digno en las sociedades europeas -o lo que hubo de conseguirse en África del Sur para que los no blancos pudieran acceder a un estatus social digno.

Así ocurriría todo esto, sin duda, vistas las cosas desde las teorías clásicas de la cultura.

Pero, en cuanto a ellas, se plantea hoy una dificultad muy grave, sin cuya resolución todo lo dicho se queda en nada. Y es la siguiente: ¿pueden ser utilizables esas teorías de la cultura para explanar lo que sucede hoy? ¿No responden a una época en que la antropología sólo se ocupaba de pueblos lejanos, cerrados sobre sí mismos y mentalmente monolíticos? ¿No se elaboraron atendiendo a situaciones que ya no existen? ¿No está en crisis el concepto de cultura para los mismos antropólogos?

\section{Crisis y transformación del concepto clásico de cultura}

La crisis se abrió hace ya unos cincuenta años, y lo hizo por dos motivos:

- Porque los pueblos hasta entonces estudiados por los antropólogos - pueblos lejanos a ellos, generalmente exóticos y prácticamente cerrados sobre sí mismos- empezaron a escasear y a convertirse en rarezas. En cualquier parte del mundo estaba ya Coca-Cola y entraban usos euroamericanos. Las formas de vida se hacían en todas partes incoherentes.

11. En los estudios sobre migraciones, se ha vuelto de uso común el planteamiento de J. W. BERrY, que, en «Immigration, acculturation, and adaptation», Applied Psychology, núm. 1, 1997, vol. 46, p. 5-34, proponía diferenciar cuatro posibles posicionamientos de los inmigrantes ante las culturas de sus países de recepción: asimilación, aculturación, exclusión y marginación. 
- Porque los antropólogos habían empezado a usar los métodos de la antropología para explanar aspectos de la vida de los países desarrollados y, en éstos, los conocimientos, las creencias y las disposiciones aparecían como en mosaicos hechos de piezas sueltas y heterogéneas. Si había cultura, era una cultura fragmentada cuya descripción antropológica no podría dar cuenta de las formas de convivencia en que los sujetos se implicaban.

Y, a pesar de todo, la práctica de la investigación antropológica y la utilización del concepto de cultura — que era su columna vertebral— siguieron adelante y siguieron mostrándose útiles para describir y explicar cuestiones de convivencia. Los mejores estudios sobre integración de los inmigrantes y sobre relaciones interculturales lo muestran ${ }^{12}$. No sin que dejen de producirse «abusos teóricos», como, por ejemplo, utilizar la idea de cultura y las metodologías asociadas a ella para dar cuenta de formas de interacción derivadas de adscripciones profesionales o ideológicas.

El que de todas formas siguieran resultando útiles los estudios basados en las clásicas teorías de la cultura, a pesar de que apenas hubiera ya países de culturas monolíticas y de que estuvieran produciéndose los abusos teóricos indicados, no podía menos de suscitar alguna clase de replanteamientos. Y, efectivamente, no han escaseado en los últimos treinta años, lo cual ha dado lugar, como innovación especialmente importante, a que se rompa con la asociación entre cultura y territorio. Y más en profundidad, a que los estudios sobre cultura se conviertan en estudios sobre la distribución social de los sistemas de significado.

Ello no cambia mucho lo que siempre se hacía en los estudios antropológicos. Simplemente obliga a tomar nota de que esa distribución de los sistemas de significado no se atiene ya hoy a criterios territoriales. Pero es verdad que el asumir este principio impone una nueva tarea a quienes van a hablar de alguna cultura: la tarea de definir bien los grupos a los que va a atribuir unas determinadas características culturales. Por ejemplo: no bastará decir «la cultura de los marroquíes" para referirse a todos los inmigrantes venidos de Marruecos. Porque es sabido que hoy, en Marruecos, la cultura no es monolítica y que, en consecuencia, son muy distintas las formas de sentir y entender de quienes provienen de las zonas rurales del Riff y de quienes provienen de las concentraciones urbanas del sur; de los que han experimentado más fuertemente el contacto con Francia y de los que se han visto menos influidos por dicho país. Y otro tanto ocurriría con la pretensión de hablar de una cultura latinoamericana (!).

Esto supuesto, sigue resultando útil y válido lo que hacían tradicionalmente los antropólogos, basándose en la clásica teoría de la cultura, para describir culturas y para explanar las frustraciones y los conflictos de quienes se ven

12. Como ejemplo en España de la utilidad de la aproximación antropológica en el estudio de las migraciones, puede citarse la investigación realizada por Dan Rodríguez sobre los matrimonios mixtos y las familias transnacionales de origen africano (ver referencia en bibliografía). 
transplantados de unas culturas a otras. Lo que ocurre es que hoy hace falta delimitar bien los grupos a que se atribuye un determinado lugar en la distribución social de los significados.

\section{Frustraciones o conflictos culturales y derechos culturales}

Una dificultad que tiene el abordar esta cuestión es que estas frustraciones y conflictos, aunque existen, no se reconocen como tales frustraciones o conflictos culturales. Por ejemplo: a un inmigrante ecuatoriano le hablan muy fuerte y él se siente tratado con violencia; seguramente dirá: «los españoles son soberbios y racistas». Y no dirá: «en comparación con Ecuador, aquí se habla como a gritos y el uso cultural es en mi país no hablar así sino cuando uno está enojado» ${ }^{13}$. Otro ejemplo: una inmigrante dominicana tiene una gran depresión. Irá al médico y él le dirá: «está viviendo el duelo por la pérdida de su país». Y, efectivamente, está haciendo duelo por la pérdida de su país, pero, en concreto, lo que ha perdido es la espontánea inserción en un sistema de referencias y de conocimientos que le son familiares por pertenecer a su cultura de origen, y es precisamente la pérdida de esa inserción lo que la deja en el vacío.

En este sentido, las frustraciones y los conflictos culturales producen heridas de segundo nivel. Es decir: heridas padecidas en un nivel más profundo que el normalmente advertido. Por eso buscaríamos en vano menciones de traumas culturales si revisamos las narraciones de las historias de vida en que los inmigrantes cuentan las dificultades por ellos experimentadas en la emigración. Nombran consecuencias exteriores de las verdaderas frustraciones culturales, las cuales básicamente se reducirían a tres capítulos ${ }^{14}$ : al de perder la posibilidad de comprender espontánea e inmediatamente las situaciones que atraviesan, al de perder su lugar acostumbrado en el sistema de las identidades que articulaba la interacción en sus ambientes de origen, y al de perder las referencias contextuales que les permitían sentirse autores responsables de su propia vida. O sea, en síntesis: los efectos de carecer, en todo o en parte, de lo que les aportaban en sus países las funciones cognitiva, identitaria y sociohistórica de las culturas respectivas.

Otra perspectiva que ayuda a captar lo que sucede con las frustraciones culturales es comparar nuestras maneras de ver el medio laboral y el «medio cultural». Ocurre, pues, que nosotros mismos y el común de los inmigrantes sabemos o creemos saber cómo es el campo de la convivencia social en que surgen las cuestiones laborales, lo cual no ocurre con lo que se refiere al campo en que se plantean las tensiones de la diversidad cultural, porque, en efecto,

13. Eso no quita que, a veces, los españoles seamos efectivamente soberbios y racistas!

14. Una descripción de los conflictos culturales experimentados por los inmigrantes y de sus formas de expresión la encontramos en la obra de Nekane BASABE, Anna ZlOBInA y Dario PÁEZ (2004), Integración socio-cultural y adaptación psicológica de los inmigrantes extranjeros en el País Vasco, Vitoria, Gobierno Vasco, Cuadernos Sociológicos Vascos, 15. 
tenemos una representación bastante concreta de cómo es el espacio o la esfera del trabajo, de lo que abarca, de la clase de actividades que incluye y de los abusos a que da lugar. Entonces podemos representarnos bastante bien la clase de problemas a que deben atender los derechos laborales. Pero no hay, en cambio, ni entre los inmigrantes ni en la población española, una representación concreta de que el campo de las relaciones culturales abarcaría al menos:

- Las situaciones en que se da por supuesta una rápida y espontánea comprensión de los mensajes implícitos en gestos y en contextos típicos de determinados colectivos.

- Las situaciones en que necesita hacerse valer la identidad personal vivida por un inmigrante, en un contexto social en el cual dicha identidad no tiene un sitio definido en el sistema de las identidades con arreglo al cual se estructuran espontáneamente las secuencias de interacción.

- Las situaciones en que el inmigrante carece del background (o trasfondo) de experiencias y conocimientos que necesitaría para poder hacerse cargo de lo que le conviene hacer o saber para mantener bajo control, en los nuevos contextos en que habita, los aspectos sociales de su línea de vida.

Pues bien: al no tener identificadas esas situaciones en que se hacen presentes desafíos culturales, tampoco se identifican los procesos de conducta a que dan lugar, los problemas que conllevan, los abusos a que darían ocasión. Y ello lleva a que ni los inmigrantes ni quienes quieren ayudarles tengan demandas concretas acerca de la consideración con que convendría o sería necesario que se les tratara en tales contextos. Y menos aún se vuelve fácil precisar y promover unos derechos culturales que pudieran proteger, a quien convive legítimamente en un espacio cultural distinto del propio, de las frustraciones y de los traumas que, por razón de su diferencia cultural, tenderán a afectarle.

$\mathrm{Y}$, sin embargo, se ha hablado mucho de derechos culturales a propósito de las pequeñas sociedades que hoy subsisten manteniendo estilos de vida primitivos y ajenos a las culturas occidentales. Hoy ya todo el mundo consideraría inadmisible que se hiciera con los indígenas amazónicos (por ejemplo) lo que hicieron españoles, portugueses, ingleses y holandeses, cuando, durante siglos, impusieron sus culturas a los pueblos a los que llegaron - como igualmente consideraría inadmisibles las ideas ilustradas según las cuales los países europeos que iban adquiriendo nuevas colonias no podían hacer nada mejor que arrancar a sus colonizados de su barbarie cultural y hacerles cuanto antes tan ilustrados como sus colonizadores.

En esto sí que ha habido un vuelco y se han hecho valer los derechos culturales desde que los años de la descolonización sacaron a luz las perturbaciones y los daños originados por la colonización cultural en las sociedades menos evolucionadas. Y por eso hoy la ingenuidad se ha vuelto inaceptable en el campo de las relaciones culturales.

Esto supone un cambio de mentalidad mucho más hondo de lo que a primera vista parece. Porque implica el paso de una racionalidad modelada con arre- 
glo al criterio de que la superioridad cultural de los pueblos desarrollados les autoriza para preciar en menos a otras culturas - a otro estilo de racionalidad en que otras culturas, aunque posean un menor desarrollo científico-tecnológico, demandan el mismo respeto práctico y teórico que las más desarrolladas.

Hablando en perspectiva jurídica, se ha dicho que un cambio tal desborda las concepciones clásicas de la modernidad, porque, conforme a éstas, la racionalidad del derecho implicaría una igualdad total bajo la ley de todos los sujetos del derecho, incompatible a primera vista con el reconocimiento de unas diferencias basadas en la respectiva adscripción cultural. Pero hoy la práctica parecería indicar que diversas situaciones requieren otro estilo de racionalidad del derecho, capaz de asumir y reconocer el pluralismo de esas adscripciones ${ }^{15}$. Pero el reconocerlo y asumirlo significaría tutelarlo en la medida en que esa tutela fuera conveniente para un ejercicio no discriminatorio de la ciudadanía. Y no es fácil traducir a normas jurídicas lo que necesitaría conseguirse para evitar los traumas culturales ${ }^{16}$.

De todas maneras, mucho de lo que sería conveniente queda abarcado por prescripciones de los derechos humanos, sobre todo si se tiene en cuenta lo que demanda implícitamente su puesta en vigor efectiva. Particularmente, interesarían los siguientes artículos:

- Artículo 2: Derecho a la no-discriminación.

- Artículo 3: Derecho a la vida, a la libertad y a la seguridad de su persona.

- Artículo 5: Derecho a no ser sometido a tratos inhumanos o degradantes.

- Artículo 7: Derecho a la igualdad ante la ley.

- Artículo 19: Derecho a no ser uno molestado a causa de sus opiniones.

- Artículo 20.2: Derecho a obtener salario igual por un trabajo igual.

- Artículo 23.4: Derecho a sindicarse para la defensa de los propios intereses.

- Artículo 26.1: Derecho a una educación elemental gratuita.

- Artículo 26.4: Derecho de los padres a escoger el tipo de educación de sus hijos.

Como se ve, esta lista de derechos es muy amplia y, si todos se hicieran efectivos, sería desde luego muy distinta la suerte de los colectivos de inmigrantes. Pero en la redacción de ellos hay diversas ambigüedades que en no pocos casos los dejan inoperantes. La principal de éstas se deriva del hecho de que, según ya se ha señalado, la filosofía política actualmente dominante considera a los derechos como referidos a sujetos individuales iguales, ignorando lo que en los mismos individuos apela a pertenencias comunitarias diferentes,

15. E. JAYME (1995), Identité culturelle et integration: Le droit international privé postmoderne, La Haya.

16. Una compilación de los documentos jurídicos internacionales que tenían que ver con el tema fue ofrecida por la FUNDACIÓN ENCUENTRO en su Cuaderno 130, Derechos culturales, una categoría subdesarrollada, Madrid, 1992. Desde entonces, no se han enriquecido mucho los enfoques ni las prescripciones. 
aunque constitutivas de su ser social. Y quedan entonces los inmigrantes desprotegidos en cuanto a los traumas de segundo nivel a los que antes nos hemos referido: los abusos a que se ven sometidos por su desorientación cognitiva, por su desajuste identitario, por la distorsión y por el estrechamiento social de sus perspectivas.

\section{Bibliografía}

Altamirano, C. (dir.) (2002). Términos críticos de la sociología de la cultura. Buenos Aires: Paidós.

APARICIO, R. (1981). Cultura y sociología. Madrid: Narcea.

ARIÑO, A. (1997). Sociología de la cultura. Barcelona: Ariel.

AUGÉ, M. (1992). Los «no-lugares». Barcelona: Gedisa.

BASABE, N.; ZlOBINA, A. y PÁEZ, D. (2004). Integración socio-cultural y adaptación psicológica de los inmigrantes extranjeros en el País Vasco. Vitoria: Gobierno Vasco. Cuadernos Sociológicos Vascos; 15.

Berger, Peter L. y LuckMann, T. (1993). La construcción social de la realidad. Buenos Aires: Amorrortu.

BERRY, J. W. (1997). "Immigration, acculturation, and adaptation». Applied Psychology, núm. 1, enero, vol. 46, p. 5-34.

Bigsby, C. W. E. (ed.) (1976). Approaches to popular culture. Londres: Edward Arnold. BRUNner, J. J.; BARRIOS, A. y CATACAN, C. (1989). Chile: Transformaciones culturales $y$ modernidad. Santiago: Flacso.

BuENO, G. (1996). El mito de la cultura. Barcelona: Editorial Prensa Ibérica.

CAÑEDO, M. El concepto de cultura y la antropología: Apuntes para una revisión crítica [en línea]. <http://www.ucm.es/info/dptoants/ateneo/montse.htm>

ClifFORD, J. (1995). Dilemas de la cultura. Barcelona: Gedisa.

- (1999). Itinerarios transculturales. Barcelona: Gedisa.

COHEN-EMERIQue, M. (1989). "Connaissance d'autrui et processus d'attribution en situations interculturelles». En: RETSCHISKY, J. y otros. La Recherche Interculturelle, tomo I. París: L'Harmattan, p. 26-46.

Duch ÁlvareZ, L. (2004). Estaciones del laberinto: ensayos de antropología. Barcelona: Herder.

EROles, C.; Gagneten, M. M. y Sala, A. (2004). Antropología, cultura popular y derechos humanos. Buenos Aires: Espacio.

ETXEBERRIA, X. (2004). Sociedades multiculturales. Bilbao: Mensajero.

FrIEDMAN, J. (1994). Cultural identity. Londres: Sage.

FundaCión ENCUENTRO (1992). Derechos culturales, una categoría subdesarrollada. Madrid. Cuaderno; 130.

GeErTz, C. (1994). Conocimiento local. Barcelona: Paidós.

- (1995). Interpretación de las culturas. Barcelona: Gedisa.

- (2002). «El mundo en pedazos: Cultura y política en el fin de siglo». En: Reflexiones antropológicas sobre problemas filosóficos. Barcelona: Paidós, p. 211-22.

GONZÁLEZ QUIRÓs, J. L. (2003). Repensar la cultura. Madrid: Ediciones Internacionales Universitarias.

Hall, J. R. y Neitz, M. J. (1993). Culture: Sociological perspectives. New Jersey: Prentice Hall.

Hall, E. T. (1981). Beyond culture. Nueva York: Anchor Book/Doubleday. 
HannerZ, U. (1998). Conexiones transnacionales. Madrid: Cátedra.

Hoffstede, G. (1984). Culture's consequences. Beverly Hills: Sage Publications.

JAYME, E. (1995). Identité culturelle et integration: Le droit international privé postmoderne. La Haya.

KeEsing, R. M. (1993). "Teorías de la cultura». En: Velasco, H. Lecturas de antropología social y cultural. Madrid: UNED, p. 43-74.

Kroeber, A. L.; Kluckhohn, C. (1952). Culture. A Critical Review of Concepts and Definitions.

Kuper, A. (2001). Cultura, la versión de los antropólogos. Barcelona: Paidós.

KyMliCKA, W. (1996). Ciudadanía multicultural. Barcelona: Paidós.

LAMO DE EsPINOSA, E. (ed.) (1995). Culturas, estados, ciudadanos. Madrid: Fundación Ortega y Gasset.

REYNOSO, C. (2000). Estudios culturales y antropología. Barcelona: Gedisa.

REYNOSO, C. (comp.) (1991). El surgimiento de la antropología postmoderna. Barcelona: Gedisa.

SARTORI, G. (2001). La sociedad multiétnica: Pluralismo, multiculturalismo y extranjeros. Madrid: Taurus.

RODRÍGUEZ GARCÍA, D. (2004). «Inmigración y mestizaje hoy. Formación de matrimonios mixtos y familias transnacionales de inmigrantes en Cataluña». Migraciones, núm. 16, p. 77-120.

Tornos, A. y RodrígueZ, M. E. (eds.) (2000). Derechos culturales y derechos humanos de los inmigrantes. Madrid: Publicaciones de la Universidad Comillas. Colección Sociedad, Cultura, Migraciones.

TYLOR, Edward B. (1976). Primitive culture: Researches into the development of mythology, phylosophy, religion, language, art and custom. Gordon Press.

Williams, R. (1980). The long revolution. Harmondsworth: Pelican. 